\title{
Special issue of the Czech society for operations research
}

\author{
Petr Fiala $^{1}$ • Josef Jablonsky ${ }^{1}$
}

This special issue presents some theoretical and application papers of operations research generated by the members of the Czech Society for Operations Research (CSOR) and collaborators. The CSOR is a quite small professional society but with increasing number of members (approx. 100 regular members) and numerous activities.

International conference Mathematical Methods in Economics (MME) is a traditional annual meeting of professionals from universities and business who are interested in the theory and applications of operations research and econometrics organized by the Czech Society for Operations Research (CSOR) together with the Czech Econometric Society in various places within the Czech Republic. The number of participants is rapidly increasing in the last years. Usually around 200 professionals are presenting their research results every year. The conferences MME cover both theoretical and application aspects of mathematical modelling of economic processes. The scope of the conference involves operations research, econometrics, mathematical economics and other related areas. Although the conference is the annual meeting of the CSOR there are always participants from all around the world especially from surrounding countries as Slovakia, Poland, Austria, Germany, Slovenia, etc. Accepted papers presented at the conference are published in the Book of Proceedings that is indexed in Conference Proceedings Citation Index (CPCI) since 2003.

The call for the special issue of CEJOR was launched during the 30th MME conference that took place in the city of Jihlava in September 2013. The conference was attended by approximately 200 participants. The special issue contains a selection

$凶 \quad$ Petr Fiala

pfiala@vse.cz

Josef Jablonsky

jablon@vse.cz

1 Faculty of Informatics and Statistics, University of Economics Prague,

W. Churchill Sq. 4, 13067 Praha 3, Czech Republic 
of accepted papers of various operations research fields. All of them were presented during the MME conference and then submitted to the CEJOR special issue.

Altogether we have received 38 submissions for the special issue. The manuscripts were reviewed by two or three anonymous reviewers and finally 13 papers were accepted for publication. The accepted papers cover a wide range of theoretical and application aspects of operations research: analytic hierarchy process, data envelopment analysis, optimal control, multiobjective optimisation, stochastic optimisation, decision theory, oligopoly theory, game theory, supply chain management, operational complexity, portfolio management, modelling the wage distribution, and advertising efficiency.

The paper (Fiala 2016) proposes a two-stage procedure for profit allocation in supply chains based on combination of non-cooperative and cooperative game approaches. Jablonsky (2016) formulates new multi-period DEA models that allow evaluation the efficiency of decision making units within the whole production chain. A deterministic infinite time horizon optimal control model (Janova and Hampel 2016) is analysed. The model is aimed to determine optimal areas forested by particular tree species in Drahanska highlands in the Czech Republic. The paper (Kankova 2016) focuses on the investigation of the relationship between "characteristics" obtained on the base of complete knowledge of the probability measure and estimates obtained on the data base, mostly in the multiobjective case. The paper (Kramulova and Jablonsky 2016) proposes an original Analytic Hierarchy Process (AHP) model for competitiveness ranking of selected countries. Krejci and Stoklasa (2016) attempting to fuzzify the AHP focus particularly on the construction of fuzzy pairwise comparison matrices and on obtaining fuzzy weights of objects from them subsequently. The paper (Lukas and Plevny 2016) concerns with analysis of operational complexity of company suppliercustomer relations. Illustrative results of operational complexity measurement using entropy are provided for two case studies. Marek and Vrabec (2016) explore the possibility of modelling the wage distribution using a mixture of density functions. The article (Mielcova 2016) applies the concept of additional weights to calculate an ex post power distribution using Shapley-Shubik power index together with Banzhaf power index on real voting data. The paper (Pekar et al. 2016) presents the alternative approach computing the weights of assets in portfolio assets based on the nonlinear measure techniques. The proposed alternative includes principles of differential evolution. Zapletal and Smid (2016) propose a mean-risk decision model for a steel company facing emission limits and trading with emission allowances. Zouhar (2016) formalises the notion of randomly ordered consumers into a new stochastic version of the proportional rationing scheme and derives the probabilistic properties of firm-specific demand under this new scheme. The paper (Zouharova et al. 2016) addresses the issue of online advertising efficiency in the context of the "banner blindness" phenomenon.

\section{References}

Fiala P (2016) Profit allocation games in supply chains. Cent Eur J Oper Res. doi:10.1007/ s10100-015-0423-6

Jablonsky J (2016) Efficiency analysis in multi-period systems: an application to performance evaluation in Czech higher education. Cent Eur J Oper Res. doi:10.1007/s10100-015-0401-z 
Janova J, Hampel D (2016) Optimal managing of forest structure using data simulated optimal control. Cent Eur J Oper Res. doi:10.1007/s10100-015-0383-x

Kankova V (2016) A remark on multiobjective stochastic optimization via strongly convex functions. Cent Eur J Oper Res. doi:10.1007/s10100-015-0414-7

Kramulova J, Jablonsky J (2016) AHP model for competitiveness analysis of selected countries. Cent Eur J Oper Res. doi:10.1007/s10100-015-0394-7

Krejci J, Stoklasa J (2016) Fuzzified AHP in the evaluation of scientific monographs. Cent Eur J Oper Res. doi:10.1007/s10100-015-0399-2

Lukas L, Plevny M (2016) Using entropy for quantitative measurement of operational complexity of supplier-customer system: case studies. Cent Eur J Oper Res. doi:10.1007/s10100-015-0386-7

Marek L, Vrabec M (2016) Using mixture density functions for modelling of wage distributions. Cent Eur J Oper Res. doi:10.1007/s10100-015-0409-4

Mielcova E (2016) Spatial power indices with applications on real voting data from the chamber of Deputies of the Czech Parliament. Cent Eur J Oper Res. doi:10.1007/s10100-015-0406-7

Pekar J, Cickova Z, Brezina I (2016) Portfolio performance measurement using differential evolution. Cent Eur J Oper Res. doi:10.1007/s10100-015-0393-8

Zapletal F, Smid M (2016) Mean-risk optimal decision of a steel company under emission control. Cent Eur J Oper Res. doi:10.1007/s10100-015-0398-3

Zouhar J (2016) PQ oligopoly, proportional rationing, and randomly ordered consumers. Cent Eur J Oper Res. doi:10.1007/s10100-015-0400-0

Zouharova M, Zouhar J, Smutny Z (2016) A MILP approach to the optimization of banner display strategy to tackle banner blindness. Cent Eur J Oper Res. doi:10.1007/s10100-015-0398-3 